\title{
TECTÔNICA EXTENSIONAL OBLÍQÜA NO SUL DO ESTADO DE SÃO PAULO
}

\author{
NOLAN MAIA DEHLER ${ }^{1}$, RÔMULO MACHADO ${ }^{2}$ \& CLAUDEMIR SEVERIANO DE VASCONCELOS ${ }^{1}$
}

\begin{abstract}
EXTENSIONAL OBLIQUE TECTONICS IN AN AREA SOUTHWEST OF THE CITY OF CAJATY, SOUTHERN SÃO PAULO STATE The geological mapping (scale: 1:50.000) undertaken southwest of Cajati City, south of São Paulo State, revealed that the several lithological associations suffered an intense deformation, responsible for a pervasive mylonitization of all lithologies. The stretching lineations and the shear sense indicators associated to this mylonitization, such as S-C foliation planes, asymmetric porfiroclasts and boudins, suggest an extensional tectonics for this deformation, with extensional component to ESE, associated to sinistral strike-slip motion. Sheath folds and synmylonitic folds, with axes parallel to the stretching lineation indicate that the non-coaxial deformation reached high values of shear strain. This deformation occured in amphibolite to greenschist facies conditions, and microstructures suggest the mylonitic fabric postdates the peak of the metamorphism. The transformation of kyanite to sillimanite suggest a decrease in pressure during progressive metamorphism. Under the presence of the kyanite indicate a previous compressive history. Later on, at a shallow structural level, crenulation and asymmetric north-vergent folds associated to discrete ruptile-ductile discret thrusts, complete the structural evolution of the investigated area. The tectonic significance of this structural pattern, in Brasiliano Orogeny scenery in this crustal segment, needs of more detailed studies.
\end{abstract}

Keywords: Extensional tectonic, kinematic, stretching lineation.

RESUMO O mapeamento geológico na escala 1:50.000 de uma área a sudoeste da cidade de Cajati, sul do Estado de São Paulo, revelou que as diversas associações litológicas identificadas sofreram uma deformação intensa, responsável por una milonitização pervasiva em todos os litotipos. As lineaç̃es de estiramento e as estruturas indicadoras do sentido de cisalhamento associadas a esta milonitização, como pares de foliações S-C, porfiroclastos do tipo $\sigma$ e boudins assimétricos, sugerem uma cinemática transtracional para esta deformação, com componente extensional de topo para ESE associada à uma componente direcional sinistral. Dobras em bainha e dobras sin-miloníticas, com eixos paralelos à lineação de estiramento, indicam que a deformação não-coaxial atingiu elevados valores de shear strain. Esta deformação ocorreu em condições metamórficas de fácies anfibolito a xisto-verde, com as microestruturas sugerindo que a trama milonítica foi implantada após o ápice metamórfico. A presença restrita de cianita, sempre instável para sillimanita, sugere decréscimo de pressão durante o metamorfismo progressivo. Além disso, a sua presença é sugestiva de uma história compressiva anterior à instalação da tectônica transtracional. Posteriormente, em nível estrutural relativamente mais raso, crenulações e dobras assimétricas com vergência para norte, associadas a discretas zonas de cisalhamento rúpteis-dúcteis de empurrão, completam a evolução estrutural da área investigada. O significado tectônico deste padrão estrutural, no cenário da Orogênese Brasiliana neste segmento crustal, encontra-se na dependência de estudos mais detalhados.

Palavras-chave: tectônica extensional, cinemática, lineação de estiramento.

INTRODUÇÃo A Geologia da porção sul do Estado de São Paulo e leste do Estado do Paraná, notadamente a região do vale do rio Ribeira de Iguape, devido a sua potencialidade metalogenética, tem sido há décadas objeto de estudos sistemáticos. Estes estudos encontram-se sintetizados em Algarte et al. (1974), Batolla Jr. et al. (1981), Biondi (1983), Stein et al. (1984), Chiodi Filho (1984), Daitx (1985), Takahashi et al. (1984, 1986), Campanha et al. (1987), Campanha (1991), Bistrichi et al. (1981), Hasui (1986), Fiori (1990), Fassbinder (1997), dentre outros. Estes autores expõem toda a complexidade das definições e correlações entre as diferentes unidades litoestratigráficas que afloram nesta região.

O presente trabalho, desenvolvido no Domínio Costeiro (sensu Complexo Costeiro de Bistrichi et al. 1981), apresenta os resultados de estudos estruturais realizados numa região localizada a sudoeste da cidade de Cajati, sul do Estado de São Paulo (Fig. 1). A área em foco foi estudada durante a execução do projeto de mapeamento geológico das folhas Jacupiranga e Rio Guaraú, na escala 1:50.000, realizado pela CPRM - Serviço Geológico do Brasil, em parceria com a Secretaria de Energia de São Paulo.

O objetivo deste trabalho é, com base no estudo das lineações de estiramento-mineral e indicadores do sentido de cisalhamento da área em questão, contribuir para o entendimento tectônico deste segmento crustal.

COMPARTIMENTACÃO TECTÔNICA REGIONAL NOS ESTADOS DO PARANÁ E SÃO PAULO O segmento crustal, que abrange os Estados de São Paulo (porção sul) e Paraná, engloba o Cinturão Ribeira (Almeida et al. 1973), entidade geotectônica implantada no brasiliano, e um núcleo composto por rochas mais antigas, prébrasilianas, retrabalhadas neste ciclo, denominado por Hasui et al. (1975) Maciço Mediano de Joinville. A partir do início da década de 80 , estas unidades geotectônicas têm sido agrupadas em diversos modelos de compartimentação tectônica regional (Kaul 1980, Kaul et al. 1984, Basei 1985, Basei et al. 1992 e 1998. Mantovani et al. 1989, Fragoso César 1991, Fragoso César et al. 1998, Campanha 1991, Siga
Ir 1995). Os diversos trabalhos que abrangem os Estados de Santa Catarina e sul do Paraná individualizam um domínio estável durante a Orogênese Brasiliana/Pan-africana (Siga $\mathrm{Jr}$. et al. 1990, Basei et al. 1998), denominado Cráton de Luis Alves (CLA) (Kaul 1979). Segundo Siga Jr. (1995), os dados geocronológicos sobre o CLA sugerem a existência de porções gnáissico-granulíticas de idade Arqueana e rochas formadas no Paleoproterozóico (2.2 a $2.0 \mathrm{Ga}$ ), na Orogênese Transamazônica. O CLA é limitado a sul pela faixa neoproterozóica Tijucas (Hasui et al. 1975) ou Cinturão Dom Feliciano (Fragoso Cesar 1980), e a norte pela Faixa Apiaí, composta essencialmente por metassedimentos de baixo grau metamórfico que compõem o Grupo Acungui (Hasui et al. 1975, Campanha 1991, Basei et al. $1992 \mathrm{e}$ 1998). Entre o CLA e a Faixa Apiaí afloram ortognaisses bandados denominados por Siga Jr. (1995) de Complexo Atuba, cujo significado tectônico/geodinâmico é ainda controverso (ver Siga Jr. et al. 1990, Siga Jr. 1995, Mantovani et al. 1989, Basei et al. 1990 e 1992, Fragoso César et al. 1998). No limite deste domínio com o CLA ocorre a suíte granítica Rio Piên (Machiavelli et al. 1991 e 1993), interpretada pelos mesmos autores como representantes de um arco magmático do Proterozóico Superior.

Com exceção da Faixa Apiaí, que engloba rochas supracrustais aflorantes a norte da zona de cisalhamento Lancinha-Cubatão (Hasui \& Oliveira In: Almeida \& Hasui 1984), as demais regiões adjacentes, no Estado de São Paulo, são ainda insuficientemente estudadas. Neste trabalho, optou-se por englobar, em um único domínio, as unidades situadas a sul desta zona de cisalhamento.

SÍNTESE REGIONAL A Faixa Apiaí é formada por uma expressiva orientação nordeste de rochas supracrustais metamorfizadas na fácies xisto-verde (Fig. 1), classicamente denominada de Grupo Açungui (Marini et al. 1967), bem como por associações de rochas metavulcanossedimentares metamorfizadas em grau mais elevado, alcançando localmente condições compatíveis com a fusão parcial, como a Formação Água Clara (Marini et al. 1967), a Sequência Perau (Piekarz 1981) e o Complexo Embu (Hasui 1975, Hasui \& Sadowski

1 - Pós-Graduando do Programa de Geoquímica e Geotectônica da USP e geólogo da CPRM-Serviço Geológico do Brasil -SUREG-SP. Rua Barata Ribeiro 357, Bela Vista, São Paulo. CEP:01308-000. e-mail: nokontiki@hotmail.com

2 - Instituto de Geociências da Universidade de São Paulo. Rua do Lago 562, Cidade Universitária, São Paulo. CEP: 05508-900. e-mail: rmachado@ @sp.br

1 - Geólogo da CPRM- Serviço Geológico do Brasil. E-mail: csvasconcelos@ hotmail.com. 
1976). Estas associações metamórficas são intrudidas por corpos granitóides cálcio-alcalinos (Fig. 1) e deformadas por um complexo arranjo de zonas de cisalhamento de alto ângulo, de movimentação direcional destral que, segundo Fiori (1992), Campanha (1991) e Silva et al. (1998), corta uma trama tectônica de baixo ângulo. Posteriormente, Hasui (1986) incluiu as citadas unidades no denominado Bloco São Paulo. São ainda problemáticas as relações estratigráficas entre as rochas incluídas no Grupo Açungui com as de grau metamórfico mais elevado, assim como as correlações estratigráficas regionais, proliferando assim denominações locais e correlações entre unidades estratigráficas distintas (ver Campanha 1991, Fassbinder 1997).

A Faixa Apiaí tem sido estudada em seus mais distintos segmentos (Soares 1988, Fiori 1990, 1992, Campanha 1991, Fassbinder 1997). Apesar das controvérsias, vários autores têm assinalado a importância das zonas de cisalhamento direcionais destrais e o papel da tectônica transpressiva no seu contex to de história evolutiva, sendo isto estendido para toda a Faixa Ribeira na região sudeste do Brasil (Dayan \& Keller 1990, Ebert et al. 1991, Corrêa Neto et al. 1993, Machado \& Endo 1993 a e b, Endo \& Machado 1993, Ebert et al. 1993 a e b, Ebert \& Hasui 1998). Este padrão deformacional seria resultado de uma tectônica colisional oblíqua, após uma subducção de crosta oceânica de posição e cinemática ainda controversas (ver Fiori 1990, Campanha 1991, Basei et al. 1992, Ebert et al. 1993 b, Reis Neto 1994,
Fassbinder 1997, Ebert \& Hasui 1998, dentre outros), ocorrida na orogênese Brasiliana/Pan-africana (Tassinari 1988, Siga Jr. 1995, Basei et al 1998, Machado et al. 1996).

O Domínio Costeiro (DC), limitado a norte pela Zona de Cisalhamento Lancinha-Cubatão, de movimentação direcional destral, estende-se para sul até o litoral (Fig. 1). Hasui (1986) denominou este domínio de Bloco Vitória. Esta delimitação corresponde à de Bistrichi et al. (1981) para o Complexo Costeiro, que seria composto no Estado de São Paulo principalmente por gnaisses indiferenciados, metamorfisados na fácies anfibolito, incluindo ainda granulitos e rochas supracrustais de baixo grau metamórfico, denominada "Seqüência Cachoeira" (Batolla Jr. et al. 1981, Silva et al. 1981), a qual foi interpretada por Silva (1981) como rochas supracrustais arqueanas, provavelmente greenstone belts. Os granulitos são representados por núcleos charno-enderbíticos isolados, em associação com gnaisses kinzigíticos e ortognaisses, como o Maciço de Itatins (Sadowski 1974) e o Complexo Serra Negra (Silva et al. 1981). As rochas gnáissicas indiferenciadas receberam várias denominações, como Complexo Gnáissico-Migmatítico (Dantas et al.1987), Complexo Pré-Setuva (Biondi, 1983) e Complexo Atuba (Siga Jr. 1995, Silva et al. 1998). Para Dantas et al. (op. cit.), a unidade gnáissica sobrepõe-se à unidade granulítica è à Sequiência Cachoeira.
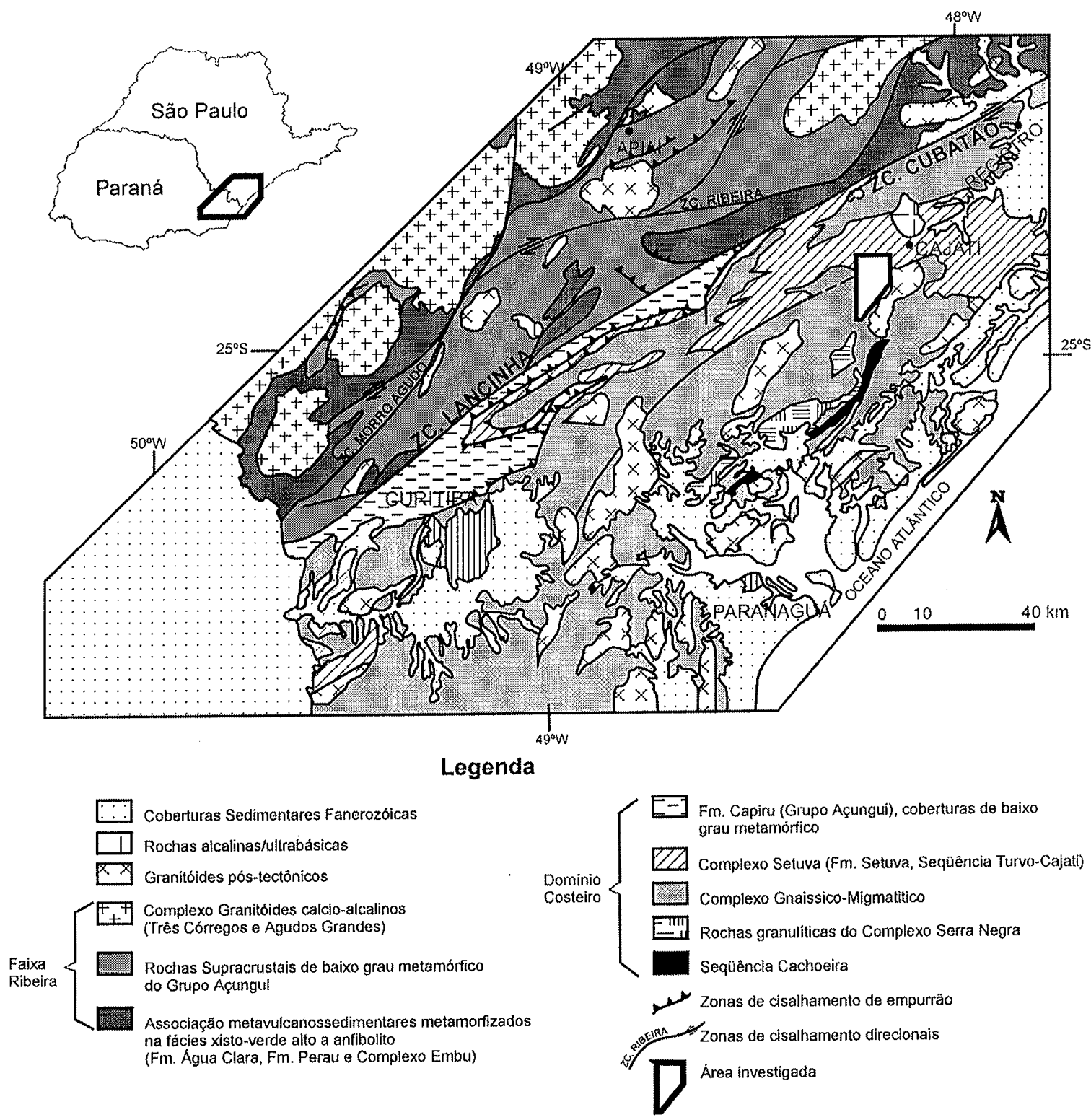

Figura 1-Mapa regional do sul do Estado de São Paulo e leste do Paraná, mostrando as principais unidades litoestratigráficas regionais $e$ os dois maiores compartimentos tectônicos (Faixa Apiaí e Domínio Costeiro) reconhecidos no sul do Estado de São Paulo (modificado de Campanha 1991). 
No DC ocorrem ainda coberturas metassedimentares metamorfisadas na fácies xisto-verde a anfibolito. No Estado do Paraná foram caracterizadas as Formações Setuva (Bigarella \& Salamuni 1956 a e b), composta por micaxistos e gnaisses, e Capiru (Bigarella \& Salamuni op. cit.), esta última considerada pelos autores como do Grupo Açungui. O posicionamento estratigráfico da Formação Setuva, sua extensão e correlações com outras unidades, é uma questão ainda não resolvida na região (ver diversos trabalhos de síntese citados no início deste artigo). Recentemente, alguns autores propuseram que pelo menos parte da Formação Setuva poderia representar uma tectonofácies correlata à Formação Capiru e seu embasamento (Fiori 1994, Yamato 1999). A porção da Formação Capiru, caracterizada por quartzitos, metapelitos e metacalcáreos, é considerada como uma sedimentação marinha plataformal (Silva et al. 1998, Yamato 1999), metamorfisada na facies xisto-verde e intensamente deformada no Neoproterozóico (Fiori 1990, Silva et al. 1998, Yamato 1999). No Estado de São Paulo, Silva et al. (1981) caracterizaram a Seqüência Turvo-Cajati que, tradicionalmente, era posicionada no Grupo Açungui (Cordani et al. 1971, Melcher et al. 1973). Silva \& Algarte (1981 a e b) e subdividiram-na em três subseqüencias sem conotação estratigráfica, designadas de "Subseqüência Cajati", de natureza metapelítica, "Subseqüência Turvo-Areado", predominantemente metapsamítica, e "Subsequiência Capela do Cedro", onde predominam mármores dolomíticos e calcíticos, e rochas cálcio-silicáticas. Os mesmos autores consideraram esta unidade como pré-Açungui. $O$ metamorfismo varia da fácies xisto-verde a anfibolito alto, alcançando localmente a anatexia (Silva \& Algarte $o p$. cit.). Hasui \& Oliveira (1984) englobam a Seqüência Turvo-Cajati no Complexo Setuva, de idade pré-Açungui.

Estudos geocronológicos recentes (Siga Jr. 1995, Picanço et al. 1998), envolvendo diferentes sistemáticas isotópicas, em rochas granulíticas e ortognáissicas do domínio em pauta, forneceram idades arqueanas e paleoproterozóicas, com idades $\mathrm{U} / \mathrm{Pb}$ concentradas em torno de $2.1 \mathrm{Ga}$, com importante retrabalhamento/migmatização no Ciclo Brasiliano. Esta evolução policíclica já havia sido assinalada por diversos autores, apesar da utilização de métodos com menor valor interpretativo (Cordani \& Bittencourt 1967, Battola Jr. et al. 1977 e 1981, Campagnoli 1996)

Estruturalmente, o DC é pouco conhecido, tendo sido desenvolvidos trabalhos envolvendo essencialmente análise geométrica (Sadowski 1974, Carneiro et al. 1979, Silva et al. 1977, Silva \& Algarte 1981 b, Campos Neto 1983, Campagnoli 1996, entre outros). Campos Neto (1983), estudando a mesma região focalizada neste trabalho, identificou uma estruturação principal em nappes anticlinais associadas a cavalgamentos, com vergência para NW. Posteriormente, Campagnoli (1996), referendou esta estruturação principal. Fiori (1992), ao estudar rochas da Formação Capiru, identificou uma estruturação imbricada em duplexes com vergência de topo para SE. Esta estruturação foi admitida como regional para o segmento do Domínio Costeiro a sul da zona de cisalhamento Lancinha-Cubatão e a norte dos terrenos granulíticos do CLA (Campanha 1991, Siga Jr 1995), correspondente à área de afloramento do Complexo Atuba. A estruturação regional deste segmento seria semelhante à estruturação proposta por Fiori (1992) para a Formação Capiru, enquanto no CLA predomina uma franca orientação noroeste das foliações miloníticas (Siga Jr. 1995).

Embora diversos autores tenham propostos, com base na teoria da tectônica de placas, modelos de compartimentação tectônica regional para o DC, são ainda escassos os dados cinemáticos disponíveis para uma avaliação efetiva destes modelos.

GEOLOGIA LOCAL Foram individualizadas três associações litológicas, que se acham representadas em mapa (Fig. 2). Estas associações são aqui descritas sem uma conotação estratigráfica. A primeira associação é composta por biotita-hornblenda gnaisses (ortognaisses) cinza, bandados a laminados, com notável trama

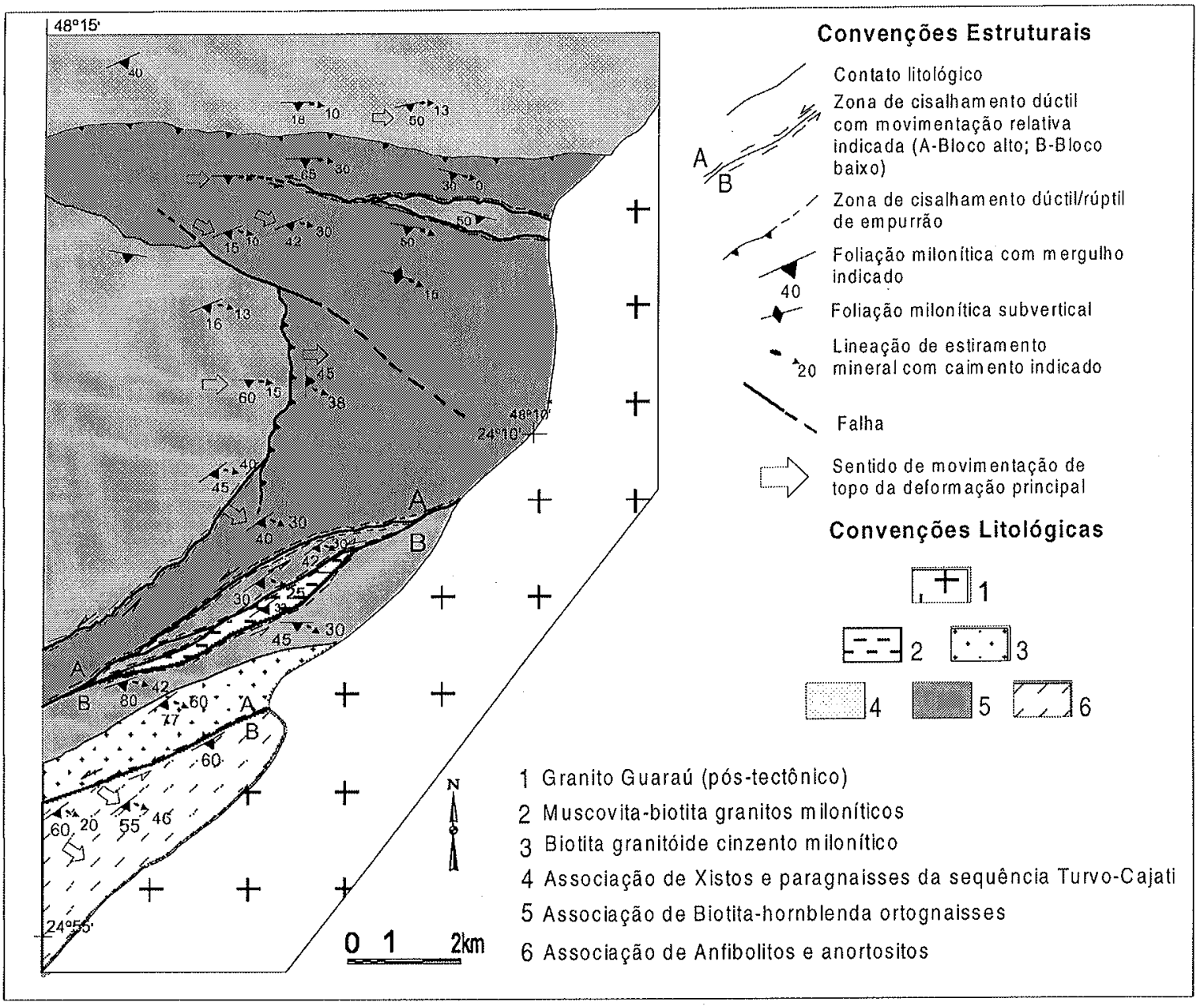

Figura 2-Mapa geológico-estrutural da área estudada. 
milonítica. São rochas de granulação fina a média, localmente porfiroclásticas. Esta unidade apresenta freqüentemente níveis boudinados de anfibolito. A leste da área investigada são frequentes boudins de rochas de composição ultrabásica (talco xistos). $O$ bandamento é dado por uma alternância composicional entre leitos claros, de composição tonalítica a granodiorítica, mais raramente granítica, e leitos máficos anfibolíticos. Estes gnaisses ocorrem tectonicamente intercalados com a associação metassedimentar, sendo correlatos aos gnaisses Capelinha e Barra do Queimado de Campos Neto (1983), e aos Gnaisses do Complexo Gnáissico-Migmatítico indiferenciado de Silva e Algarte (1981 a e b), considerado como embasamento das associações metassedimentares.

A segunda associação, correlata à sequência Turvo-Cajati (Silva e Algarte 1981 a) e aos xistos Capelinha e Forquilha de Campos Neto (1983), é caracterizada por (sillimanita)-(estaurolita)-(granada)-biotitamoscovita xistos grossos, com subordinações de (cianita)-sillimanitamoscovita-biotita gnaisses e sillimanita-granada-biotita-muscovita gnaisses migmatíticos, mármores dolomíticos, quartzitos micáceos e rochas cálcio-silicáticas. Ocorrem também granitos miloníticos a duas micas, concordantes com a estruturação geral das rochas encaixantes, mapeáveis na escala do trabalho efetuado (Fig. 2).

A terceira associação, sobreposta tectonicamente às duas anteriores, é composta por (biotita)-hornblenda anfibolitos melanocráticos, de granulação média a grossa, contendo intercalações de anortositos e gnaisses tonalíticos subordinados, nestes últimos sendo característica a presença de quartzo azulado. No contato desta associação com a associação metassedimentar, encaixado em zonas de cisalhamento de alto ângulo (Fig. 2), ocorre expressivo corpo de biotita granito cinza a rosado, milonítico a protomilonítico, de direção ENE, contendo enclaves microgranulares dioríticos.

GEOLOGIA ESTRUTURAL Estruração Principal As rochas na área estudada são caracterizadas por uma conspícua foliação milonítica, penetrativa em todas as litologias. Nos ortognaisses (primeira associação) a foliação é materializada pela orientação preferencial dos minerais constituintes, sendo paralela a um bandamento composicional muito regular e de espessura variável, com estrutura frequientemente laminada, de aspecto listrado. Nestas mesmas rochas, lâminas e/ou bandas de anfibolito, de espessura milimétrica até decimétrica, intercalam-se com níveis mais claros de espessura similar, mostrando contatos extremamente retilíneos e contínuos por dezenas de metros. A regularidade e o caráter rítmico entre as bandas/lâminas destes gnaisses, são muito semelhantes à estrutura dos gnaisses descritos como straight gneisses por Smit \& Van Reenen (1997). As bandas de anfibolito mostram freqüentemente estruturas pinch-and-swell e boudins, com zonas de estricção seccionadas por bandas de cisalhamento dúcteis extensionais. As rochas xistosas da associação metassedimentar apresentam uma foliação milonítica em domínios (Hobbs et al. 1976), grossa e anastomosada, conferindo uma marcante geometria lenticular aos xistos. Estas rochas, quando migmatizadas, apresentam uma foliação milonítica paralela ao bandamento composicional, onde bandas lenticulares de composição granítica, freqüentemente com foliações oblíquas aos contatos, intercalam-se com bandas ricas em minerais micáceos. As rochas anfibolíticas apresentam uma foliação milonítica anastomosada, localmente paralela a um bandamento composicional, onde bandas melanocráticas, ricas em hornblenda, intercalam-se com bandas ricas em plagioclásio. Nas rochas de composição tonalítica desenvolve-se uma foliação milonítica grossa em domínios. Nesta unidade é marcante o caráter heterogêneo da deformação, tendo sido observadas porções menos deformadas com estruturas primárias preservadas.

Em projeção estereográfica (Fig. 3a, b, c e d), as foliações miloníticas mostram uma distribuição geral semelhante em todas as associações mapeadas, embora hajam diferenças aparentes entre as distribuições dos pólos. Exceto para o domínio onde os ortognaisses têm uma orientação da foliação milonítica próxima de $\mathrm{N}-\mathrm{S}$, com mergulhos moderados para $\mathrm{E}$ (Fig. 3b), o estereograma geral das foliações, para as rochas desta unidade (Fig. 3a), mostra uma concentração bem marcada que sugere uma estruturação em baixo ângulo com mergulho para SSE. Este padrão é mais complexo nos metassedimentos, ocorrendo concentrações principais compatíveis com planos de foliação orientados EW, com mergulhos variáveis para S (máximos: 28 a $62^{\circ}$ ), e concentrações secundárias que também delineiam guirlandas compatíveis com planos orientados NE-SW e NW-SE, e mergulhos baixo a alto, para $\mathrm{S}$ (Fig. 3c). Em ambos os grupos, no entanto, as guirlandas são incompletas, não ocorrendo planos com mergulhos para norte, exceto em planos subverticais. Nos anfibolitos e granitóides, aflorantes no extremo sul da área (Fig. 2), as foliações são de direção ENE e mergulhos íngremes para SSE (Fig. 3d).

Nos planos da foliação milonítica desenvolve-se uma forte lineação de estiramento mineral observada em quase todos os afloramentos. Nos ortognaisses (primeira associação) e nos anfibolitos (terceira associação), esta lineação é materializada por cristais ou agregados de hornblenda, feldspato e biotita estirados. Nos metassedimentos (segunda associação), a lineação é dada por agregados de sillimanita, quartzo, feldspato e micas. Esta lineação, em projeção estereográfica, mostra uma concentraç̃o consistente para N108 e N107, com caimento variando de 24 a $34^{\circ}$ nos ortognaisses e metassedimentos, respectivamente (Fig. $3 \mathrm{e}$ e 3g). Nos anfibolitos, as lineações têm direção semelhante, mas com uma obliquidade maior, caindo em torno de $50^{\circ}$ (Fig. 3f). Na maior parte dos afloramentos descritos, desenvolvem-se tramas planares e lineares, caracterizando tectonitos S-L e, secundariamente, tectonitos L.

$\mathrm{Na}$ área mapeada são observadas dobras com a superfície axial paralela à foliação milonítica principal. De modo geral, estas estruturas afloram localmente, predominando amplamente estruturas planares que não delineiam dobras. Em perfil, as dobras observadas são fechadas a isoclinais, com flancos adelgaçados, localmente rompidos, e zonas apicais espessadas (dobras da classe 3 de Ramsay 1967). Localmente são dobras do tipo similares ou da subclasse $1 \mathrm{C}$, por vezes desenraizadas, com zonas de charneira preservadas em microlithons na foliação milonítica. Estas zonas de charneira mostram-se associadas freqüentemente com estruturas lineares do tipo mullions. Os eixos destas estruturas são sub-paralelos à lineação de estiramento-mineral (Fig. 3h). Localmente, são observados eixos curvos nas zonas de charneira de dobras em bainha (Fig. 4a).

Cinemática da Deformação Principal As estruturas assimétricas indicativas do sentido de cisalhamento observadas foram os pares de foliações SC (Berthé et al. 1979, Lister \& Snoke 1984), porfiroclastos do tipo sigma (Passchier \& Simpson 1987) e boudins sigmoidais (Goldstein 1988). Estas estruturas sugerem, consistentemente, movimentação oblíqua com componente extensional de topo para ESE e componente direcional sinistral. Associam-se também zonas de cisalhamento direcionais sinistrais, e extensionais, com lineação de estiramento down-dip. Esta variação dos movimentos é dada por uma mudança de oblíqüidade da lineação de estiramento-mineral na foliação milonítica, porém mantendo-se sempre paralela nos domínios de foliações de baixo e alto ângulo. A figura 4 mostra exemplos de estruturas indicativas do sentido de rotação do fluxo durante a deformação principal. Nos ortognaisses laminados observam-se zonas de cisalhamento discretas, associadas à dobras assimétricas com rompimento paralelo à superfície axial. Estas zonas discretas promovem o descolamento e transporte do bandamento com cinemática compatível com a sugerida por outras estruturas.

As bandas anfibolíticas nos ortognaisses apresentam estruturas do tipo boudins e pinch-and-swell, que são seccionadas na região de estricção por bandas de cisalhamento extensionais com cinemática sintética em relação à movimentação principal (Fig.4h). Esta relação implica a rotação antitética dos segmentos boudinados, originando estruturas back-rotated com relação ao sentido de fluxo principal (Hanmer, 1986). Ocorrem com freqüência mobilizados graníticos em zonas surréicas dos boudins, sugerindo que a deformação ocorreu em condicões metamórficas da fácies anfibolito.

Estruturas Tardias As estruturas tardias, superpostas à estruturação principal, são representadas por dobras assimétricas, crenulações e zonas de cisalhamento dúcteis-rúpteis de empurrão. Estas estruturas não são abundantes na área. As dobras são de perfis abertos a suaves, com zonas de charneira de geometria em geral cilíndrica, assimétricas, com vergência geral para norte. Os eixos destas estruturas, em estereograma, apresentam concentração para 108/11 e secundariamente para 091/18 (Fig.3e). O desenvolvimento destas estruturas é local, restringindo-se à escala de afloramento.

As zonas de cisalhamento tardias, mapeadas nos contatos basais da unidade de ortognaisses com os metassedimentos, apresentam orientação variável ENE-WSW a N-S. Estas zonas são caracterizadas, geometricamente, por um arranjo anastomosado de planos micáceos discre- 


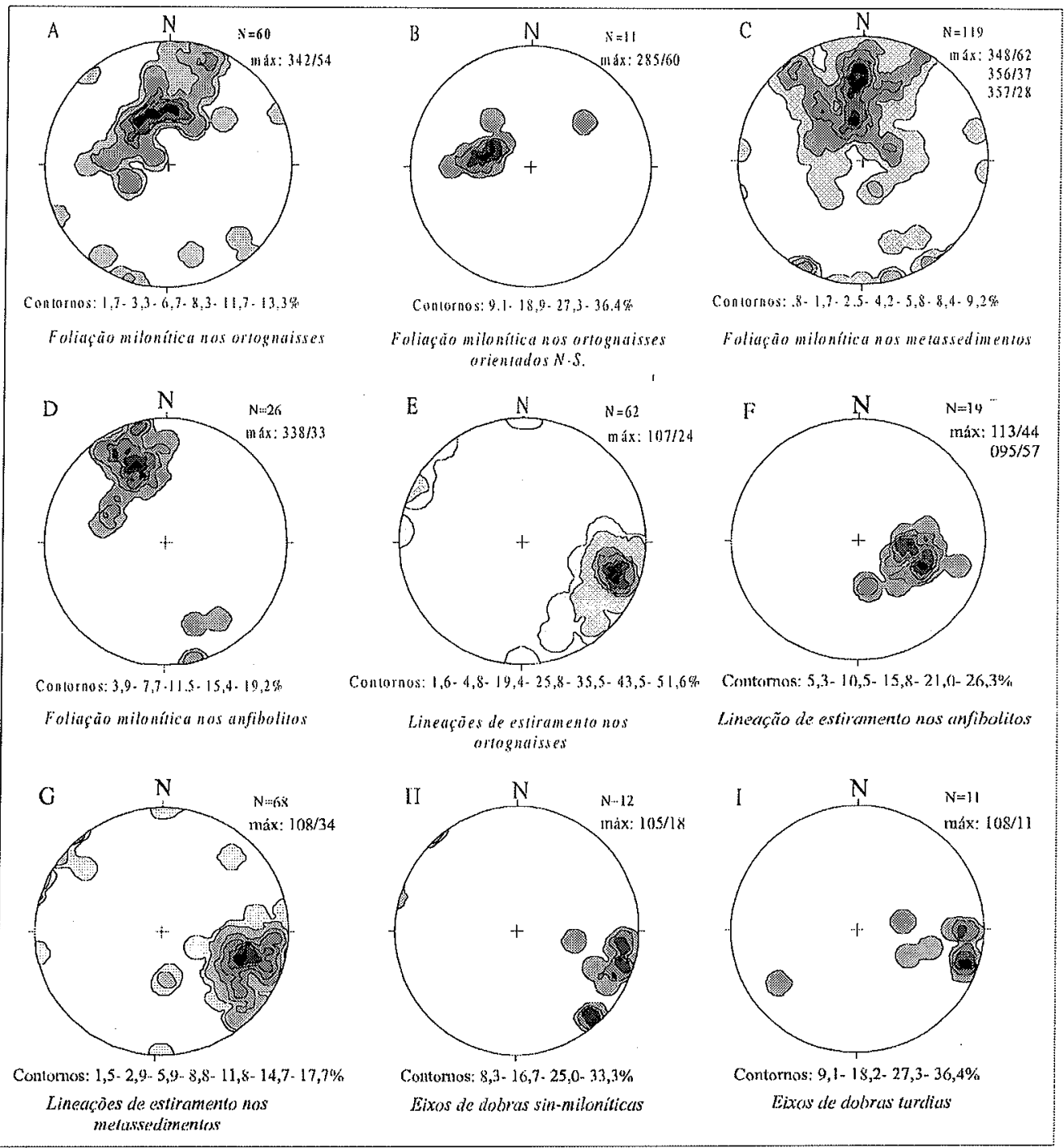

Figura 3 - Projeções estereográficas (hemisfério inferior) dos pólos da foliação milonítica principal e das lineaçöes de estiramento-mineral em rochas das diferentes associaçós, e dos eixos de dobras sín-miloníticas e tardias na área mapeada.

tos, espaçados, que cortam o bandamento anterior. A geometria das estruturas sigmoidais sugere movimentação geral de empurrão para norte, em nível estrutural relativamente mais raso.

DISCUSSÃO E CONCLUSÕES As associações litológicas mapeadas foram sujeitas a uma fase de deformação principal, associada a um cisalhamento não coaxial, responsável pela geração de uma forte foliação milonítica e de uma lineação de estiramento mineral, penetrativas em todos os litotipos. Os indicadores cinemáticos sugerem um sentido de cisalhamento sinistral oblíqüo, com componente extensional de topo para ESE. Além disso, associam-se movimentos direcionais sinistrais. A explicação destas estruturas é compatível com um regime cinemático transtracional, como discutido originalmente por Harland (1971).

Geometricamente, pode-se considerar a cinemática caracterizada neste trabalho como o resultado de empurrões dobrados com vergência para E-SE. Contudo, os dados levantados em toda a área do projeto não favorecem esta interpretação pelos seguintes aspectos: (i) ausência de domínios estruturados em baixo ângulo por empurrões com vergência para E-SE, nas duas folhas 1:50.000 mapeadas, tanto a norte quanto a sul da área em questão; (ii) ausência de estruturas dobradas em escala de mapa; (iii) ausência de uma distribuição simétrica de unidades correlatas, que justifique a interpretação de empurrões dobrados.

A existência de uma foliação milonítica principal com mergulhos de baixo a alto ângulo (Fig. 3), contendo lineação de estiramento mineral sempre paralela, é aqui interpretada como resultado da partição da deformação num regime deformacional transtrativo. Isto é reforçado pela escassez na escala de afloramento de dobras posteriores a esta foliação.

A estruturação principal finita de toda a área é compatível em termos geométricos com planos sigmoidais mergulhando para sul (Fig.3). Os domínios de alto ângulo são materializados por zonas de cisalhamento direcionais e oblíquas com componente extensional na parte norte, passando para oblíquas extensionais, a sul. Apesar desta variação, as lineações de estiramento são paralelas em ambos os segmentos e a cinemática é compatível com o desenvolvimento sincrônico destas estruturas. Este regime deformacional ocorreu em condições de metamorfismo da fácies anfibolito, no grau médio de Winkler (1979), sendo compatível com a deformação dúctil do plagioclásio e de anfibólios nos ortognaisses e anfibolitos.

O paralelismo entre os eixos das dobras sin-miloníticas com a lineação de estiramento mineral indica deformação cisalhante intensa, alcançando valores elevados de shear strain (Escher \& Watterson 1973, Williams 1978). Esta deformação foi responsável pelo giro dos eixos das dobras para a direção de transporte, levando à geração de dobras em bainha (Cobbold \& Quinquis 1980, Alsop 1992, Mies 1993).

O significado regional desta tectônica extensional necessita ainda de estudos estruturais, microtectônicos, metamórficos e geocronológicos complementares.

Observações efetuadas em lâminas delgadas permitiram avaliar e discutir alguns aspectos importantes entre metamorfismo e deformação. A presença de cristais bem formados de moscovita em contato 


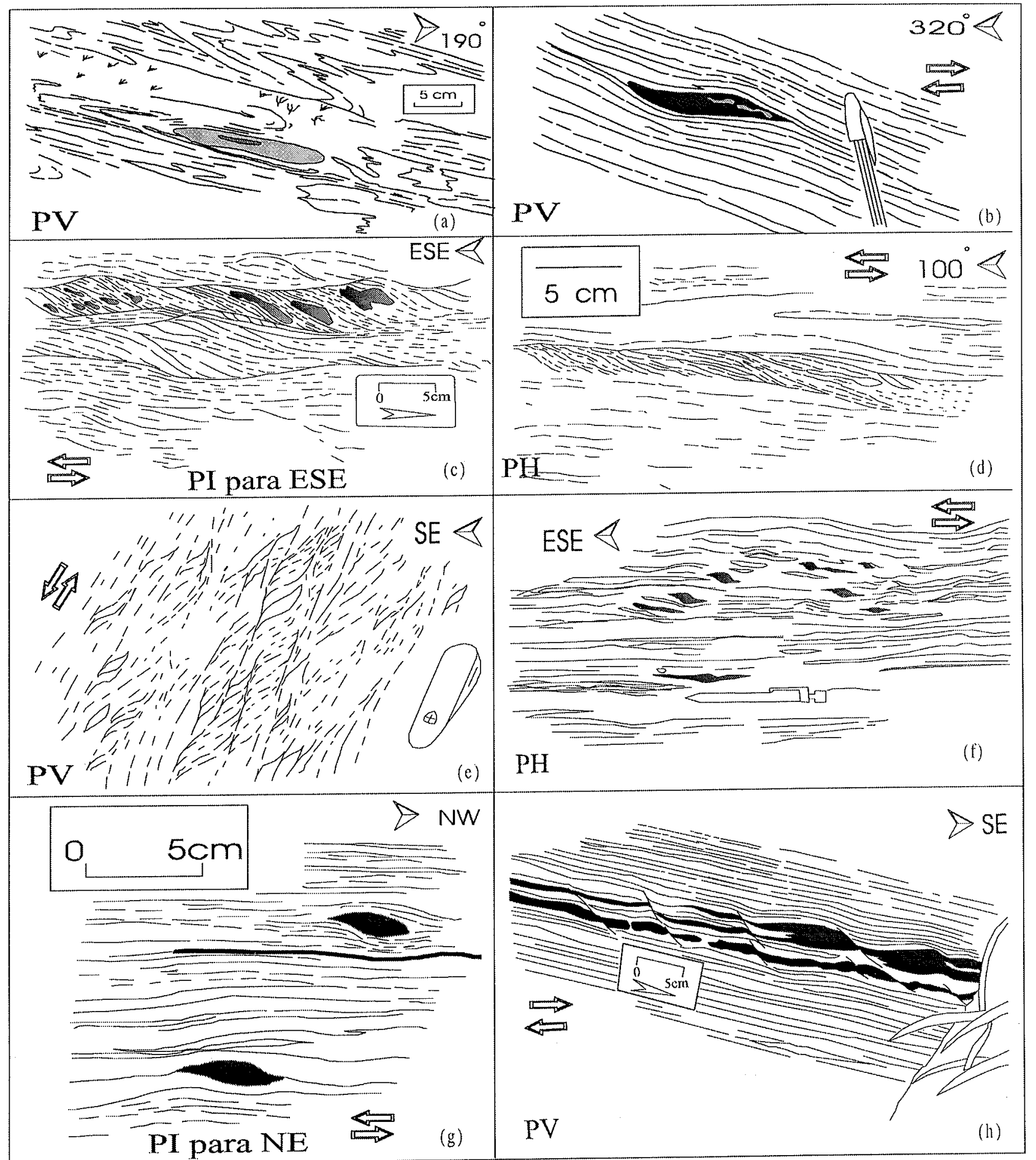

Figura 4 - Desenhos feitos a partir de fotos de afloramentos de estruturas indicadoras do sentido de cisalhamento. (4a)- seção paralela ao plano ZY do elipsóide de deformaça finita de dobra em bainha: (4b e g)-boudins assimétricos; $4 c$, d e e)-Pares de foliaçoes $S$ - $C ;$ (4f)- porfinoclastos assimétricos do tipo s; (4h)de deformaçäo finita de dobra em bainha; ( 4 b e g)-boudins assimétricos; (4c, a e e)-Pares de foliaçố vertical; PI-Plano inclinado; Seções subparalelas ao plano $\mathrm{XZ}$ do elipśríde de deformação finita.

com quartzo em rochas metapelíticas é compatível com o grau médio (Winkler 1979). Os minerais ocorrem em arranjos planares e lineares no plano da foliação milonítica principal, sugerindo que a deformação principal ocorreu em condições de pressão e temperatura em que esta paragênese é estável. Outra relação paragenética importante é presença de cianita e sillimanita (fibrolita), sendo esta última a fase dominante e ocorre substituindo a cianita, inclusive com a formação de pseudomorfos, uma evolução do caminho PTt para o metamorfismo no sentido horário. A presença do par cianita e sillimanita sugere que a migmatização tenha ocorrido em condições de pressões intermediárias
(Myashiro 1973, Yardley 1989), como já assinalado por Silva \& Algarte (1981 a) e Campagnoli (1996). Uma questão a ser esclarecida é se esta transformação é devida somente a um aumento de temperatura, ou se ela ocorreu por um decréscimo substancial da pressão no metamorfismo progressivo. Com base na tectônica caracterizada neste trabalho, a segunda hipótese parece no momento a mais plausível Por outro lado, a ausência de evidências petrográficas conclusivas, de que as rochas metassedimentares e ortoderivadas teriam sofrido retrogradações generalizadas durante a fase de milonitização principal é sugestivo de que o padrão tectônico identificado neste trabalho foi 
implantado numa crosta previamente espessada durante o mesmo evento metamórfico. Em lâmina delgada, todos os litotipos apresentam feições características de recristalização dinâmica, notadamente no quartzo. Os contatos de grãos são irregulares e reentrantes. Os cristais mostram feições como bandas de deformação e extinção ondulante. Observam-se texturas de manto e núcleo, com coexistência de grãos poligonizados, por vezes livres de deformação nas bordas, com porfiroclastos exibindo bandas de deformação e extinção ondulante e subgrãos. Estas características microestruturais favorecem a interpretação de recristalização dinâmica (Hobbs et al. 1976, Passchier \& Trouw 1997). Esta feição é instável (Passchier \& Trouw op cit.), sugerindo que a deformação instalou-se após o pico do metamorfismo e foi seguida por resfriamento relativamente rápido, a julgar pela abundância de minerais hidratados.

Os dados geocronológicos disponíveis sobre a área estudada sugerem idade Neoproterozóica para a deformação e metamorfismo a partir de protólitos paleoproterozóicos (Cordani \& Bittencourt 1967, Siga Jr 1995, Campagnoli 1996). Campagnoli (1996) obteve idades de resfriamento $(\mathrm{K} / \mathrm{Ar}$ ) de $565 \pm 39 \mathrm{Ma}$, em hornblenda dos ortognaisses, de $527 \pm 26 \mathrm{Ma}$, em biotita do mesmo afloramento e, de $587 \pm 21 \mathrm{Ma}$, em flogopita de metassedimentos. Estes dados foram interpretados pelo autor como idades mínimas da deformação milonítica. Datações U/Pb em zircōes efetuadas por Vasconcelos et al. (1999), em corpo de biotita granito do contato entre as rochas básicas e os metassedimentos, forneceram a idade de $740 \pm 140 \mathrm{Ma}$, que é aqui interpretada como idade máxima para a deformação.

Inúmeros autores têm relacionado a tectônica extensional ao ambiente compressivo associado ao espessamento de crosta continental, decorrente da subducção ou colisão continental. Esta tectônica, descrita nos Andes (Dalmayrac \& Molnar 1981), nos Himalaias (Royden \&
Burchfield 1987) e no oeste norte-americano (Coney \& Harms 1984), tem sido associada classicamente ao colapso gravitacional de segmentos das porções mais elevadas de cadeias orogênicas, sendo esta uma feição típica da crosta superior a média. Por outro lado, Doglioni (1995) relaciona outros processos que poderiam explicar esta mesma tectônica em ambientes compressivos. $\mathrm{Na}$ área estudada é ainda prematura a vinculação das zonas de cisalhamento transtrativas a um modelo genético. E possível que o regime tectônico caracterizado neste trabalho represente uma feição local, originado pela variação da orientação ou pela terminação de zonas de cisalhamento, ou então ele possa representar uma feição tectônica regional, cujo significado deve ser ainda investigado.

Em função do modelo proposto e dos dados até então disponíveis, cabe salientar a existência de uma possível relação entre a tectônica evidenciada neste trabalho e os granitos alcalinos da suíte Serra do Mar. Este magmatismo tem sido interpretado como associado a um provável ambiente extensional no intervalo de 550 a $600 \mathrm{Ma}$ (Kaul 1997. Siga Jr. 1995). Na área em questão ocorre o batólito do Guaraú, orientado aproximadamente $\mathrm{N} 30 \mathrm{E}$, que compõe o limite oriental da área estudada (Fig. 3). Embora este corpo corte a trama tectônica das rochas encaixantes, ele poderia estar vinculado geneticamente ao regime tectônico caracterizado no presente trabalho.

Agradecimentos À Secretaria de Energia do Estado de São Paulo e à CPRM - Serviço Geológico do Brasil, pelo suporte financeiro e operacional; ao Prof. Dr. Yociteru Hasui pelas discussões no campo; aos geólogos Arlindo Akio Yamato e Paulo Cézar Santarém da Silva da CPRM-BH, pelas discussões e ajuda com diversas ilustrações; ao Prof. Dr. Hardy Jost e dois revisores anônimos, cujas sugestões foram importantes para a melhoria do trabalho.

\section{Referências}

Algarte J. P., Daitx E. C., Cunha H. C. da S., Cavalcante J. C., Yamamoto K., Kaefer L. Q. Chieregati L. A. 1974. Projeto Sudeste do Estado de Säo Paulo: Follha São Patlo (SF.23-Y-C) - relatório final. São Paulo, DNPM/CPRM, $5 \mathrm{vol}$.

Almeida F. F. M., Amaral G., Cordani U. G., Kawashita K. 1973. The precambrian evolution of the south american cratonic margin south of Amazon river. In: E. M. Nairn \& F G. Stehli (eds.) The ocean basins and margins. New York, Plenun, $411-446$.

Alsop G. I. 1992. Progressive deformation and the rotation of contemporary fold axes in the Ballybofey Nappe, north-west Ireland. Geological Joumal, 27:271-283.

Basei M. A. S. 1985. O Cinturão Dom Feliciano em Santa Catarina. São Paulo. Inst. de Geociências, Universidade de São Paulo, São Paulo, Tese de Doutoramento, 185p.

Basei M. A. S., Siga Jr. O., Machiavelli A. 1990. Tectonic relationship between the Dom Feliciano Belt and the Joinville Massif, Southern Brazil. In: SBG, Workshop "Geoquímica Isotópica, Lito-Geoquímica e Geocronologia das Regiões Sul e Sudes"Geoquímica Isotopica, Lito-Geoquimica e Geocronologiad

Basei M. A. S., Siga Jr. O., Machiavelli A., Mancini F. 1992. Evolução tectônica dos terreM. A. S., Siga Jr. O., Machiavelli A., Mancini F. 1992 . Evolução tectonica dos terrenos entre os cinturões Ri
Geociencias, 22:216-221.

Basei M. A. S., McReath I., Siga Jr. O. 1998. The Santa Catarina Granulite Complex of Southern Brazil: A Review. Gondwana Research, 1:383-391.

Batolla Júnior F., Hama M., Lopes Júnior I. 1977. Idades radiométricas $\mathrm{Rb} / \mathrm{Sr}$ e K/Ar em rochas cristalinas da regiăo leste do Paraná. In: SBG, Simpósio Regional de Geologia, 1, São Paulo, Atas, 324-337.

Batolla Júnior F., Silva A. T. S. F. da, Algarte J. P. 1981. O pré-cambriano na região sulsudeste do Estado de São Paulo e este-nordeste do Estado do Paraná. In: SBG, Simpósio Regional de Geologia, 3, Curitiba, Atas, 1:94-108.

Berthé D., Choukroune P., Jegouzo P. 1979. Ortho-gneiss, mylonite and non-coaxial deformation of granites: the exemple of the south Armorican shear zone. Journal of deformation of granites: the exem
Structural Geology, 1:31-42.

Biondi J. C. 1983. Mapa geológico da área do embasamento do Estado do Paraná, esc.: 1: 250.000 . Curitiba, MINEROPAR.

Bigarella J. J. \& Salamuni R. 1956 a. Estudos preliminares na Série Açungui V: estruturas orgânicas nos dolomitos da Formação Capiru - PR. Dusenia, 7:317-323.

Bigarella J. J. \& Salamuni R. 1956 b. Estudos preliminares na Série Açungui VI: algumas estruturas singenéticas nos dolomitos da Formação Capiru. Arquivo de Biologia Tecnica, pp.: 11-97.

Bistrichi C. A., Carneiro C. D. R., Dantas A. S. L., Ponçano W. L., Campanha G. A. C. Nagata N., Almeida M. A., Stein D. P., Melo M. S., Cremonini O. A. 1981. Map, geológico do Estado de Säo Paulo, escala 1:500.000. São Paulo, IPT/PRÓ-MINÉRIO/PROMOCET, 126p. (volumel).

Campagnoli F. 1996. Consideraçóes sobre a geologia da Sequência Turvo-Cajati, na reuão do alto Rio Jacupiranguinha, SP. Inst. de Geociências, Universidade de São Paulo, São Paulo, Dissertação de Mestrado, 93p.

Campanha G. A da C. 1991. Tectônica proterozóica no alto e médio Vale do Ribeira, esrados de São Paulo e Paraná. Inst. de Geociências, Universidade de São Paulo, São Paulo, Tese de Doutoramento, 296p.

Campanha G. A. da C., Bistrichi C. A., Almeida M. A. 1987. Considerações sobre a organização litoestratigráfica e evolução tectônica da faixa de dobramentos Apiaí. In SBG, Simpósio Sul-Brasileiro de Geologia, 3, Curitiba, Atas, 2:725-742.

Campos Neto M. C. 1983. Os gnaisses do alto Jacupiranguinha e xistos Cajati: relaçõe estruturais e estratigráficas. In: SBG, Simpósio Regional de Geologia, 4, São Paulo, Atas, pp: $91-102$.
Carneiro C. D. R., Santoro E., Rodrigues E. P., Hasui Y. 1979. Evoluçăo geológica do précambriano da Baixada Santista. In: SBG, Simpósio Regional de Geologia, 2, Rio Claro, Atas;, 1:31-45.

Chiodi Filho C. 1984. Contribuição a geologia das regiões sul paulista e leste paranaense, grupos Açungui e Setuva. In: SBG, SBG, Congresso Brasileiro de Geologia, 33, Rio de Janeiro, Atas, 5:2394-2406.

Cobbold P. R. \& Quinquis H. 1980. Development of sheath folds in shear regimes. Journal of Structural Geology, 7:119-126.

Coney P. J. \& Harms T. A. 1984. Cordilleran metamorphic core complexes: Cenozoic extensional relicis of Mesozoic compression. Geology, 12:550-554

Cordani U. G. \& Bittencourt I. 1967. Determinações de idades potássio/argônio em rochas do Grupo Açungui. In: SBG, Congresso Brasileiro de Geologia, 21, Curitiba, Anais, pp.: 159-165.

Cordani U. G., Girardi V. A. V., Gomes C. B., Lellis H. S., Melcher G. C., Melfi A. J. 1971 Geologia da folha Eldorado (SP). In: SBG, Congresso Brasileiro de Geologia, 25 São Paulo, Anais, Boletim Especial, pp.: 176.

Corrêa Neto A. V., Dayan H., Valença J. G., Rafael Cabral A. 1993. Geologia e estrutura da zona de cisalhamento do Rio Paraíba do Sul entre Três Rios - RJ e Sapucaia - RJ. In: SBG. Simpósio de Geologia do Sudeste, 3, Rio de Janeiro, Atas, pp.: 194-200

Daitx E. C. 1985. Uma análise crítica dos chamados grupos Sefuva e Açungui na região do Vale do Ribeira ( $S P$ e $P R$ ). Inst. de Geociências, Universidade de São Paulo, São Paulo, Exame de Qualificação, 178p.

Dalmayrac B.\& Molnar P. 1981. Parallel thrust and normal faulting in Peru and constraints on the state of stress. Earth and Planefary Science Letters, 55:473-481.

Dantas A. S. L., Gimenez Filho A., Teixeira L. A., Nagata N., Fernandes L. A., Albuquerque Filho J. L., Frascá M. H. B. de. 1987. Geologia das folhas Juquiá (SG.23-V-A-I-4) e Miracatu (SG.23-V-A-II-3) do Estado de São Paulo. São Paulo. DMGA/IPT, 2 vol. (Relatório 25.371)

Dayan H. \& Keller J. V. A. 1990 . A zona de cisalhamento do Rio Paraíba do Sul nas vizinhanças de Três Rios - RJ: uma análise da deformação dada por algumas feições estruturais. Revista Brasileiva de Geociências, 19:494-506.

Doglioni C. 1995. Geological remarks on the relationships between extension and convergent geodynamic setting. Tectonophysics, 252:253-268.

Ebert H. D. \& Hasui Y. 1998. Transpressional tectonics and strain partitioning during oblique colision between three plates in the precambrian of south-east Brazil. In: $R$. E. Holdsworth, R. A. Strachan, J. F, Dewey (eds.) Continental transpressional and transtensional tectonics, London, Geological Society Special Publication, 135:231 252.

Ebert H. D., Hasui Y., Costa J. B. S. 1991. O caráter transpressivo do cinturão transcorrente rio Paraíba do Sul. In: SBG, Simpósio Nacional de Estudos Tectônicos, 3, Rio Claro, Boletim de Resumos Expandidos, 139-141.

Ebert H D. Neves M. A., Hasui Y., Szatmari P., Aires J. R. 1993 a. Evolução dos cinturōes de cisalhamento entre os blocos São Paulo, Vitória e Brasília através da tectônica colisional oblíqua - uma modelagem física. In: SBG. Simpósio Nacional de Estudos Tectônicos, 4, Belo Horizonte, Anais, bol. 12:254-258.

Ebert H. D., Hasui Y., Sartorato G., Almeida S. H., Costa J. B. S. 1993 b. Arcabouço es trutural e tectônica transpressiva das faixas móveis da borda sul e sudeste do cráton do São Francisco e da Sintaxe de Guaxupé. In: SBG, Simpósio Nacional de Estudos Tectônicos, 4, Belo Horizonte, Anais, bol. 12:166-171. 
Endo I \& Machado R. 1993. Sistema de cisalhamento Transatlântico: um modelo tectônico . encsion cional de Estudos Tectônicos ,4, Belo Horizonte, Anais, bol, 12:356-359

Escher A. \& Watterson J. 1973. Stretching fabrics, folds and crustal shortening Tectonophysics, 22:223-231.

Fassbinder E. 1997. A unidade Água Clara no contexto do Grupo Afungui: um modelo transpressivo de colisão obliqua no neoproterozóco paranaense. Inst. de Geociências, Universidade de São Paulo, São Paulo, Tese de Doutoramento, 207p.

Fiori A. P. 1990. Tectônica e estratigrafía do Grupo Açungui a norte de Curitiba. Inst. de Geociências, Universidade de São Paulo, São Paulo, Tese de Livre Docência, 261p.

Fiori A. P. 1992. Tectônica e estratigrafia do Grupo Açungui - PR. Boletin do Ig-USP, Série Cientifica, 23:55-74.

Fiori A. P. 1994. Evolução geológica da bacia Açungui. Boletim Paranatense de Geologiat, 42:1-27.

Fragoso César A. R. S. 1980. O Cráton do Rio de La Plata e o Cinturão Dom Feliciano no Escudo Uruguaio-Sul Riograndense. In: SBG, Congresso Brasileiro de Geologia, 31 , Camboriú, Anais, 5:2879-2892.

Fragoso César A. R. S. 1991. Tectônica de placas no ciclo brasiliano: as orogenias dos cinturöes Dom Feliciano e Ribeira no Rio Grande do Sul. Inst. de Geociências, Universidade de São Paulo, São Paulo, Tese de Doutoramento, 367p.

Fragoso César A. R. S., Machado R., Phillip R., Mello F, M., Endo I., Nummer A. R. Preciozzi G. L., Fambrini G. L., Sayeg H. 1998. Terrenos suspeitos a sul da Placa Sanfranciscana (SE da plataforma sul-americana). In: SUG, Congresso Uruguaio de Geologia, 2, Punta del Este, Atas, pp.: 1-5.

Goldstein A. G. 1988. Factors afecting the kinematic interpretation of asymetric boudinage in shear zones. Journal of Strucfural Geology, 10:707-716.

Hanmer $S$. 1986. Asymetrical pull-aparts and foliation fish as kinematic indicators. Journol of Structural Geology, 8:111-122.

Harland W. D. 1971. Tectonic transpression in caledonian Spitsbergen. Geological Magazine, 108:27-42

Hasui Y 1975 . Geologia da folba São Roque. Boletin do Ig-USP, 6:157-183

Hasui Y 1986. Novo modelo geológico do Vale do Ribeira. São Paulo. IPT, 296p (Relatório 23. 742).

Hasui Y. \& Sadowski G. R. 1976. Evolução geológica do pré-cambriano na região sudeste do Estado de São Paulo. Revista Brasileira de Geociências, 6:182-200.

Hasui Y. \& Oliveira M. A. F. 1984. A Província Mantiqueira - Setor Central. In: F. F. M Almeida \& Y. Hasui (coord.) O Pré-Cambriano do Brasil. São Paulo, Ed. Edgard Blücher, $378 \mathrm{p}$.

Hasui Y., Carneiro C. D. R., Coimbra A. M. 1975. The Ribeira Folded Belt. Revista Bra sileira de Geociências, 5:257-262.

Hobbs B. E., Means W. D., Williams P. F. 1976. An outline of structural Geology: New York, John Wiley \& Sons, 571 p.

Kaul P F.T. 1979. Precambriano e eopaleozóico do nordeste de Santa Catarina e leste do Paraná: reavaliação de dados e correlação com a África. In: SBG, Simpósio Regional de Geologia, 2 Rio Claro, Atas, 1:1-15.

Kaul P F T 1980 O Cráton de Luis Alves. In: SBG, Congresso Brasileiro de Geologia, 31 Camboriú, Anais, 5:2677-2683.

Kaul P. F T 1997 O magmatismo na Serra do Mar é adjascências (sul do Brasil) no final do Neoproterozótico e seus condicionantes tectônicos. Inst. de Geociências, Universo Neoproterozotco e seus condicionantes rectonicos. Inst. de Geo

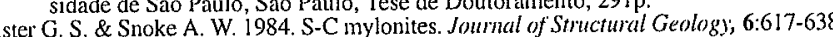

Machado N., Valladares C. S., Heilbron M., Valeriano C. M. 1996. U/Pb geochronology of the central Ribeira belt: implications for the evolution of brasiliano orogeny. Precambrian Research, 79:347-361.

Machado R. \& Endo I. 1993 a. A megaestrutura em flôr positiva do Vale do Rio Paraíba do Sul no Rio de Janeiro e suas implicações tectônicas regionais. In: SBG, Simpósio de Geologia do Sudeste, 3, Rio de Janeiro, Atas, pp. 208-213.

Machado R. \& Endo I. 1993 b. Cinturão de Cisalhamento Atlântico: um exemplo de tectônica transpressiva neoproterozóica. In: SBG Simpósio Nacional de Estudos tectonica transpressiva neoproterozica. 12:189-191

Machiavelli A., Basei M. A. S., Siga Jr. O. 1991. Geoquímica e geocronologia das granicóides deformados da região de Piên (PR). Provável arco magmático do granitóides deformados da região de Piên (PR). Provavel arco magmãico do Resumos, 1:249-253.

Machiavelli A 1. Su Aranitica Rio Piên: um arco

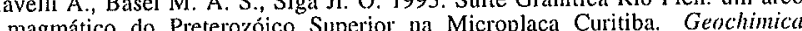
nagmatico do Preterozo

Vasconcellos A. C. B. C. 1989. Modelo gravimétrico das principais descontinuidades crustais nos terrenos précambrianos dos estados do Paraná e de Santa Catarina. Revista Brasileira de Geociências, 19:367-374.

Marini O. J. Trein E., Fuck R. A. 1967. O Grupo Açungui no Estado do Paraná. Boletim Paranaense de Geologia, 23/25:43-104.

Melcher G. C Gomes C. B. Cordani U. G., Bettencourt J. S., Damasceno O, E. C., Girard V A V. Melfi A J 1973. Geologia e petrografia das rochas metamórficas e A. graniticas associadas ao val

Mies J W 1993 . Structural analysis of sheath folds in the sylacauga marble group, talladeg slate belt, southern appalachians. Joumal of Structural Geology, 15:983-993.
Myashiro A. 1973. Metamorphism and Metamorphic Belts. London, George Allen and Unwin, 492p.

Passchier C. W. \& Simpson C. 1987. Porphyroclast system as kinematic indicators. Joumul of Structural Geology, 8:831-843.

Paschier C W \& Trouw R A J 1996. Microtectonics. Berlim, Springuer-Verlag, 289p.

Pisn J Tassinari C C G. Cordani U G. Nutman A P 1998 Idades U-Pb (SHRIMP) $\mathrm{Sm} / \mathrm{Nd}$ e Rb/Sr em rochas do Maciço de Itatins (SP): Evidências de Evolução Policiclica Anais da Academia Brasileira de Ciências, 70:139-150.

Piekarz G. F. 1981. Reconhecimento de unidades correlacionáveis à sequêencia mineralizad do Perau, estado do Paraná. In: SBG, Simpósio Regional de Geologia, 3, Curitiba Atas, 1:148-154.

Ramsay J. G. 1967. Folding and fracturing of rocks. New York, McGraw-Hill, 568p.

Reis Neto J. M. 1994. Faixa Itaiacoca: registro de uma colisão entre dois blocos continentais no neoproterozóico. Inst. de Geociências, Universidade de São Paulo, São Pauio, Tese de Doutoramento, $253 \mathrm{p}$

Royden L. H. \& Burchfield B. C. 1987. Thin-skinned N-S extension within the converge Himalayan region: gravitational collapse of a Miocene topographic front. In: M. P. COWARD, J. F. DEWEY, P. L. HANCOCK (eds.) Continental Extensional Tectonics. Geological Society Special Publication, 28:611-619.

Sadowski G. R. 1974. Tectônica do complexo magmatítico da Serra de Cubatão. In: SBG Congresso Brasileiro de Geologia, 28, Porto Alegre, Anais, boletim especial, 1:557 561

Siga Jr. O. 1995. Domínios tectônicos do sudeste do Paraná e nordeste de Santa Catarina geocronologia e evolução crustal. Inst. de Geociências, Universidade de São Paulo, São Paulo, Tese de Doutoramento, 212p.

Siga Jr. O., Basei M. A. S., Kawashita K. 1990. Perfil térmico K/Ar através do maciço de Joinville (PR e SC) e do cinturão Dom Feliciano (SC) - implicações tectônicas. In SBG, Congresso Brasileiro de Geologia, 36, Natal, Anais, 6:2773-2785.

Silva A. T. S. F. 1981. Tentativa de interpretação da gênese e evolução da infraestrutur arqueana exposta entre Peruíbe e Curitiba, SP e PR. In: SBG, Simpósio Regional de Geologia, 3, Curitiba, Atas', pp.: 133-147.

Silva A T. S.\& Algarte J. P. 1981 a. Contribuição à geologia da sequência Turvo-Cajati entre o Rio Pardo e Pariquera-Açu, Estado de São Paulo I: litologia e petrografia. In: SBG Simpósio Regional de Geologia, 3, Curitiba, Atas, 1:109-120

Silva A. T. S. \& Algarte J.P. 1981 b. Contribuição à geologia da sequência Turvo-Cajat entre o Rio Pardo e Pariquera-Aç, Estado de São Paulo. II: estrutura, metamorfismo entre o Rio Pardo e Pariquera-Açu, Estadó de São Paulo. II: estrutura, metamorfismo 1: $121-132$.

Silva A. T. S. F., Chiodi Filho C., Chiodi D. K., Pinho Filho W. D. 1977. Projero Sanros Istuupe, São Paulo, DNPM/CPRM, 3 vol.

Silva A. T. S. F., Francisconi O., Godoy A. M., Batolla Júnior F. 1981. Projeto integração e detalhe geológico no Vale do Ribeira: relatório final, São Paulo, DNPM/CPRM $5 \mathrm{vol}$

Silva P. C. S., Yamato A., Antunes V., Vasconcelos C. S., Lopes Jr. I. 1998. Projeto Folh Curitiba (SG. 22-X-D-I): relatório final, São Paulo, CPRM, $91 \mathrm{p}$

Smit C. A. \& Van Reenen D. D. 1997. Deep crustal shear zones, high-grade tecronites, and associated metasomatic atteration in the Limpopo belt, south Africa: implications for deep crustal processes. Joumal of Geology', 105:37-57.

Soares P. C. 1988 . Tectônica colisional em torno do Bloco Paraná. In: Congresso Latino Americano de Geologia, 7, Belém, Atas, 1:63-79.

Stein D P 1984 Grupo A gungui estado de conhecinento. Inst. de Geociências, Universidade de São Paulo, São Paulo, Exame de Qualificação, 30p.

Taka São Paulo, CPRM/PRO-MINÉRIO, 2 vol.

Takahashi A. T. Theodorovicz A., Câmara M. M., Godoy H. K., Moraes S. M. 1986 Projeto Engenheiro Maia - Ribeinão Branco, São Paulo, CPRM/PRO-MINÉRIO, 3 vol.

Tassinari C. C. G. 1988. As idades das rochas e dos eventos metamórficos da porção S do estado de SP e suat evoluçáo crusfal. Inst. de Geociências, Universidade de São Paulo, São Paulo, Tese de Doutoramento, 336p

Vasconcelos C.S. Dehler N.M., Yamato A., Lopes Jr. I. 1999. Projeto Jacupiranga-Rio Guaraú (escala: 1:50.000). Relatório final. São Paulo, CPRM/Secretaria de EnergiaSP, $233 \mathrm{p}$

Williams $G$. 1978. Rotation of contemporary folds into the $X$ direction during overthrus processes in Laksefjord, Finmmark. Tectonoplysics, 48:29-40.

Winkler H. 1979. Petrogenesis of Metamorphic Rocks. New York, Springuer-Verlag, 348p

Yama A A 1999 Mapeanento geolósico de parte da follha Bocailiva do Sul (SG.22-X D-I-2). Escala 1:50000. Inst. de Geociências, Universidade de São Paulo, São Paulo, Dissertaç̃o de Mestrado, $108 \mathrm{p}$

Yardley B W Detomorphic Petrology. London, Longman Earth and Sciences Series, $248 \mathrm{p}$
Manuscrito A-1124

Recebido em 25 de setembro de 1999

Revisão dos autores em 15 de maio de 2000 Revisão aceita em 20 de maio de 2000 